\title{
Suppression of exaggerated neuronal oscillations by oxytocin in a rat model of Parkinson's disease
}

\author{
Oytun Erbas ${ }^{1}$, Fatih Oltulu ${ }^{2}$ and Dilek Taskiran ${ }^{1}$ \\ ${ }^{1}$ Department of Physiology, Ege University School of Medicine, 35100 Izmir, Turkey \\ 2 Department of Histology and Embryology, Ege University School of Medicine, 35100 Izmir, Turkey
}

\begin{abstract}
Increased oscillatory activity has been demonstrated in the basal ganglia of Parkinson's disease (PD) patients. The aim of the present study was to evaluate the effects of oxytocin (OT) on local field potentials (LFPs) in a rotenone-induced rat model of PD. Adult male Sprague-Dawley rats were unilaterally injected with rotenone ( $3 \mu \mathrm{g} / \mu \mathrm{l}$ in DMSO) into the left substantia nigra pars compacta whereas vehicle group was received only DMSO. PD-developed rats were then administered either OT $(160 \mu \mathrm{g} / \mathrm{kg} /$ day, i.p. $)$ or saline for three weeks. Following treatment period, LFPs were recorded from the left striatum of freely moving rats and neuronal cell loss was evaluated by Nissl staining. We found significant increase in all frequency bands except delta in saline group when compared with vehicle $(p<0.0005)$, while treatment of OT prevented these alterations in electroencephalography (EEG) recordings. Besides, histopathological evaluation of the striatal sections revealed a significant cell loss $(p<0.005)$, whereas administration of rats with OT significantly lessened the neuronal death. These findings suggest that injury of dopaminergic neurons triggers exaggerated neuronal oscillations in the striatum and oxytocin may have some inhibitory effects on neuronal activity in PD.
\end{abstract}

Key words: Parkinson's disease - Rotenone - EEG - Oxytocin

Abbreviations: DA, dopamine; DBS, deep brain stimulation; EEG, electroencephalography; EMG, electromyography; GA, glutamate decarboxylase; LFPs, local field potentials; 6-OHDA, 6-hydroxydopamine; OT, oxytocin; PD, Parkinson's disease; ROS, reactive oxygen species; SNc, substantia nigra pars compacta; STN, subthalamic nucleus; TH, tyrosine hydroxylase.

\section{Introduction}

Parkinson's disease (PD) is one of the most common neurodegenerative disorders that produce muscular rigidity, bradykinesia, resting tremor and loss of postural balance. The principle pathology of $\mathrm{PD}$ includes selective and progressive loss of dopaminergic neurons in the substantia nigra and depletion of striatal dopamine. Although the etiopathogenesis of PD is still not fully understood, mounting evidence suggests that combination of factors including excitotoxic cell damage, environmental and genetic factors may have roles in the development of disease (Dauer and Przedborski 2003; Greenamyre et al. 2003; Cannon and Greenamyre 2011).

Correspondence to: Dilek Taskiran, Department of Physiology, Ege University School of Medicine, Bornova-Izmir, Turkey

E-mail: dilek.taskiran@ege.edu.tr
Rotenone, a well-known pesticide, rapidly crosses cell membrane due to its lipophilic structure and causes selective degeneration of the nigrostriatal dopaminergic pathway by inhibiting mitochondrial complex I. The rotenone-induced PD model appears to be an exact model in that complex I inhibition results in specific histological and behavioral symptoms similar to that observed in PD patients (Alam and Schmidt 2002; Cannon et al. 2009).

Several studies have indicated the importance of neuronal oscillations in physiological processes such as diurnal rhythms of the sleep-wake cycle, perception, memory and motor functions (Buzsaki 2002; Vandecasteele et al. 2007; Rutishauser et al. 2010). On the other hand, exaggerated oscillatory activity has been recorded in the external and internal segments of the globus pallidus and subthalamic nucleus in PD patients (Brown 2003, 2006). Recent clinical reports have demonstrated that dopaminergic drugs signifi- 
cantly reduce oscillatory activity in nigrostriatal pathway, suggesting a role of oscillations in the pathophysiology of PD. Furthermore, the degree of reduction in oscillatory activity following treatment correlates with the clinical improvement of motor symptoms (Brown 2006; Kühn et al. 2006).

Oxytocin (OT), a neurohypophyseal nanopeptide, exerts several important physiological functions, including regulation of uterus contraction during parturition and milk ejection reflex during lactation (Gimpl and Fahrenholz 2011). OT and its receptor are expressed extensively throughout the body suggesting the various paracrine and endocrine activities of OT (Gutkowska and Jankowski 2009; Gimpl and Fahrenholz 2011). Oxytocin has a wide spectrum of central and peripheral roles both in males and females including sexual and maternal behavior, social recognition, aggression, neuromodulation, cognition and tolerance (Gutkowska and Jankowski 2009; Gimpl and Fahrenholz 2011). Besides, it elicits anti-inflammatory and anti-oxidant effects in ischemia-reperfusion injury and sepsis-induced multiple organ damage via maintaining a balance of antiinflammatory and pro-inflammatory cytokines (Iseri et al. 2005; Alizadeh et al. 2012). Recently, in vitro and in vivo studies have suggested the stimulatory effect of OT on cell viability against neuronal cell death (Bakos et al. 2012; Leuner et al. 2012).

In the present study, we aimed to explore the alterations in electrophysiological activity in a rat model of PD by recording local field potentials (LFPs) and whether OT has any influence on the electrophysiological activity of PD rats.

\section{Materials and Methods}

\section{Animals}

Twenty-one adult male Sprague-Dawley rats (200-240 g) were included in the study. All animals were kept on a $12 \mathrm{~h}$ light/dark cycle with lights on (8:00 a.m.) and lights off $(8: 00$ p.m. $)$ at room temperature $\left(22 \pm 2^{\circ} \mathrm{C}\right)$. They were fed by standard pellet diet and tap water ad libitum through the study. The experimental procedures employed in the study were approved by the Institutional Animal Care and Ethical Committee of Ege University.

\section{Chemicals}

All chemicals were purchased from Sigma Chemicals (St. Louis, MO, USA) unless otherwise indicated.

\section{Stereotaxic surgery}

Animals were divided randomly into two groups: 1) rotenone group $(\mathrm{n}=14)$, and 2 ) vehicle (DMSO, $n=7)$. Rotenone-induced PD model was performed stereotaxically, as described previously (Xiong et al. 2009). Briefly, rats were deeply anesthetized by the combination of ketamine hydrochloride $\left(40 \mathrm{mg} / \mathrm{kg}\right.$, Alfamine ${ }^{\circledR}$, Alfasan International B.V. Holland) and xylazine hydrochloric ( $4 \mathrm{mg} / \mathrm{kg}$, Alfazyne ${ }^{\circledR}$, Alfasan International B.V. Holland) i.p. and placed in a stereotaxic frame. Stereotaxic coordinates were calculated according to the rat brain atlas of Paxinos and Watson (Paxinos and Watson, 1998). Rotenone ( $3 \mu \mathrm{g} / \mu \mathrm{l}$ in DMSO) was injected into the left substantia nigra pars compacta (SNc, AP: $5.0 \mathrm{~mm}$, L: $2.0 \mathrm{~mm}$, DV: $8 \mathrm{~mm}$ ) with a 28 -gauge Hamilton syringe. Sham-operated rats received only vehicle (1 $\mu$ l DMSO) instead of rotenone. The needle was left at the target site for an additional five minutes for complete diffusion of the drugs. All animals were injected penicillin (i.m.) to prevent postsurgical infection. One rat from DMSO group died during the first 24 hours of drug administration and was excluded from the study. After surgery, rats were monitored daily for behavior and health conditions. All rotenone-treated rats were developed PD-like symptoms such as hypokinesia, freezing and flexed posture within the 7-10 days following stereotaxical surgery. A summary of the study design is presented in Figure 1.

\section{Apomorphine-induced rotation test}

The extent of the rotenone lesion was assessed behaviorally 10 days after rotenone injection by challenge with apomor-

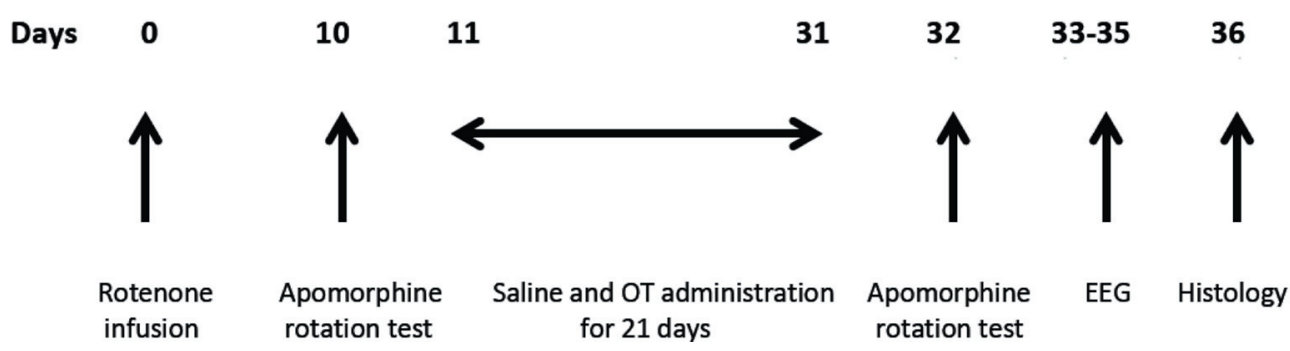

Figure 1. Schematic diagram of study design. 
phine $(2 \mathrm{mg} / \mathrm{kg}$, i.p. dissolved in saline contains $0.01 \%$ ascorbic acid). After apomorphine injection, the rats were placed on a platform $(1 \times 1$ meter $)$ and full 360 degrees unilaterally turns in a $10 \mathrm{~min}$ period were recorded. The model was considered successful in those animals that made $\geq 70$ full unilaterally rotations in $10 \mathrm{~min}$ (Jin et al. 2008). Rotation test was repeated at the end of treatment protocol to evaluate the effect of OT on rotenone toxicity.

\section{Oxytocin treatment}

Following rotation test, the valid PD rats were randomly divided into two groups of seven animals each. Group 1 $(n=7)$ was administered saline $(1 \mathrm{ml} / \mathrm{kg} /$ day, i.p. $)$ and Group $2(n=7)$ was administered Oxytocin (Pituisan ${ }^{\circledR}$, Alfasan International B.V. Holland) $160 \mu \mathrm{g} / \mathrm{kg} /$ day (i.p.) through three weeks.

\section{Electrophysiological recordings}

Electroencephalography (EEG) recordings were performed following saline and OT treatments. LFPs were recorded from the left striatum of awake and freely moving rats in a plastic box. Briefly, on the day of experimentation, rats were deeply anesthetized by mixture of ketamine $(40 \mathrm{mg} /$ $\mathrm{kg}$, i.p.) and xylazine $(4 \mathrm{mg} / \mathrm{kg}$, i.p.) and bipolar semimicroelectrodes (Polyamide-coated stainless steel wires, $0.1 \mathrm{~mm}$ diameter and electrical resistance $<1 \Omega / 10 \mathrm{~mm}$ ) were implanted into the left striatum (AP: $0 \mathrm{~mm}, \mathrm{~L}: 3.4$, DV: $5.2 \mathrm{~mm}$ ) under stereotaxic conditions. A reference electrode was placed in the skull above the ipsilateral cerebellar hemisphere. The implanted electrodes were linked to a microconnector and fixed to the skull with dental cement. When rats became active $1-2 \mathrm{~h}$ after the surgery, there were allowed to return to their cages. Animals were allowed at least $48 \mathrm{~h}$ to recover from the surgery (Erbas et al. 2012a). All registrations were made from 9:00 to 12:00 $\mathrm{h}$ in the morning. After the initial baseline session, striatal LFPs were registered for $30 \mathrm{~min}$ in the range of $1-60 \mathrm{~Hz}$ via Biopac MP30 system and converted to power spectral density algorithm with a frequency resolution of $\sim 1 \mathrm{~Hz}$. LFPs were amplified $(10000 \times)$ and band pass filtered $(0.3-1500$ $\mathrm{Hz}$ ). The raw EEG spectra of striatum were averaged for 30 minutes and same procedure was employed for each of the five frequency bands: delta $(1-4 \mathrm{~Hz})$, theta $(4-8 \mathrm{~Hz})$, alpha $(8-12 \mathrm{~Hz})$, low beta $(12-20 \mathrm{~Hz})$ and high beta $(20-30 \mathrm{~Hz})$. Figure 2 validates the histological position of the electrode in the striatum.

\section{Histopathological evaluation}

The extent of the rotenone lesion was examined quantitatively in the striatum by Nissl staining. Briefly, following electrophysiological recordings, all animals were anesthetized and perfused with $200 \mathrm{ml}$ of $4 \%$ formaldehyde in $0.1 \mathrm{M}$ phosphate-buffer saline (PBS). After the brains were removed, they were moved into $30 \%$ sucrose and stored at $4^{\circ} \mathrm{C}$ until infiltration was complete. The brains were cut coronally on a frozen sliding microtome at $40 \mu \mathrm{m}$ and mounted on gelatinized glass slides. The striatal sections were stained with cresyl violet for visualising general morphology and total cell count. All sections were examined and photographed with Olympus C-5050 digital camera at Olympus BX51 microscope. Total neuron counts were performed in six sections per studied group by an image analysis system (Image-Pro Express 1.4.5, Media Cybernetics, Inc. USA).

\section{Tyrosine hydroxylase immunostaining}

For immunohistochemistry, sections were incubated with $\mathrm{H}_{2} \mathrm{O}_{2}(10 \%)$ for 30 min to eliminate endogenous peroxidase

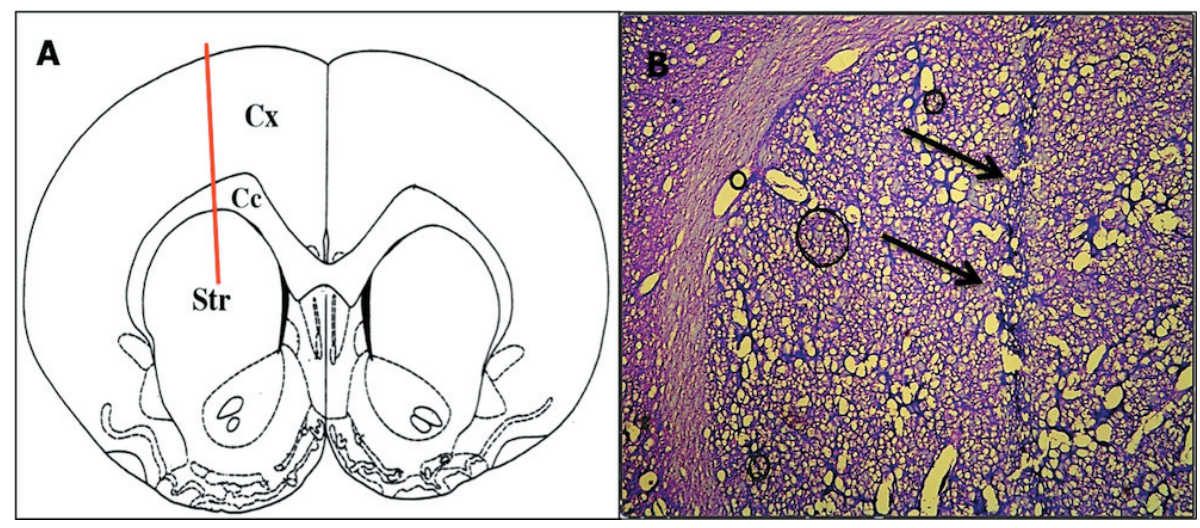

Figure 2. A. Schematic diagram illustrating recording site in the striatum (according to Paxinos and Watson 1998). B. Histological verification of the position of the EEG electrode in a striatal section (arrows indicate the electrode placement). 


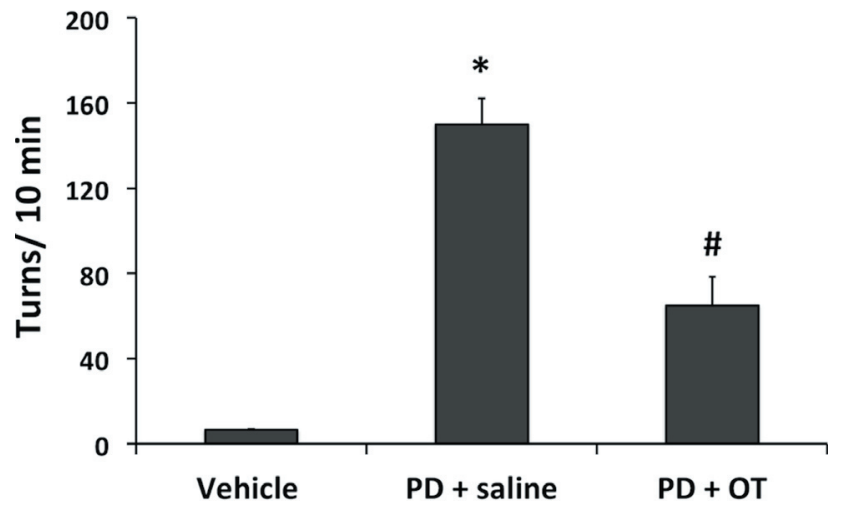

Figure 3. Results of apomorphine-induced rotational test following saline and OT treatments in PD rats. The number of rotations was significantly higher in saline-treated group compared to vehicle (DMSO) group. OT-treated rats showed a significant decline in apomorphine-induced rotations compared to saline group. Data are the mean \pm S.E.M. ${ }^{*} p<0.0005 v$ s. vehicle; ${ }^{\#} p<$ 0.005 vs. saline-treated group. OT, oxytocin; PD, Parkinson's disease.

activity and then blocked with $10 \%$ normal goat serum (Invitrogen) for $1 \mathrm{~h}$ at room temperature. The sections were then incubated in primary antibodies (tyrosine hydroxylase, Chemicon; $1 / 100$ ) for $24 \mathrm{~h}$ at $4^{\circ} \mathrm{C}$. Antibody detection was carried out with the Histostain-Plus Bulk kit (Invitrogen) against rabbit IgG and 3,3' diaminobenzidine (DAB) was used to visualize the final product (Xiong et al. 2009). All sections were washed in PBS and photographed with Olympus C-5050 digital camera mounted on Olympus BX51 microscope. Tyrosine hydroxylase (TH) immunostaining in the striatal sections was quantified by determining intensity per area using Image J software (National Institutes of Health, Bethesda, MD). The intensity measurements were performed in three striatal sections of each brain and 8-10 microscopic fields in each section.

\section{Statistical analysis}

All quantitative data were analyzed by one-way ANOVA, followed by Tukey's HSD post-hoc tests. The $p$-value of $<0.05$ was considered to indicate a significant difference between two groups. All data were presented as the mean \pm S.E.M.

\section{Results}

Apomorphine-induced rotation test

Apomorphine-induced rotational behavior was evaluated prior to OT treatment to confirm rotenone-induced PD model. All rotenone injected rats made $\geq 70$ full unilaterally rotations in $10 \mathrm{~min}$ and accepted as PD. Following treatment period, rotation test was repeated to assess the effect of OT treatment. Saline-treated PD rats showed significantly higher rotational numbers compared to vehicle group $(p<0.0005)$. However, OT treatment significantly diminished the rotational behavior compared to rats receiving saline $(65 \pm$ 14.42 and $150 \pm 12.25$ turns/10 min, respectively) $(p<0.005$, Fig. 3).

\section{Evaluation of cell injury in the striatum}

Dopaminergic cell loss in the striatal sections was further confirmed by Nissl staining and TH immunostaining. As shown in Fig. 4, total count of Nissl-stained striatal neurons confirmed a significant cell loss in saline-treated group, while DMSO group revealed a regular morphology in the striatum $(p<0.0005)$. However, striatal cell loss was significantly reduced by OT treatment compared to saline-treated group $(p<0.005)$. Similarly, there was a considerable decrease in TH immunoreactivity of saline group compared to vehicle $(p<0.05)$ whereas OT treatment significantly lessened the loss of $\mathrm{TH}+$ neurons in the striatum $(p<0.05$, Fig. 5).

\section{EEG analysis}

In the present study, power spectral analysis technique was utilized to quantify changes in striatal LFPs obtained from rats, as mentioned earlier in the methods. One-way ANOVA revealed a significant difference between the groups for all bands $(p<0.0005)$. Fig. 6 demonstrates the striatal EEG recordings in all groups and Fig. 7 describes the alterations in frequency bands as delta $(1-4 \mathrm{~Hz})$, theta $(4-8 \mathrm{~Hz})$, alpha $(8-12 \mathrm{~Hz})$ and beta $(12-30 \mathrm{~Hz})$. Post-hoc Tukey HSD test revealed a marked decrease in delta band in saline-treated rats when compared with vehicle-treated rats $(p<0.0005)$. However, treatment with OT completely reversed the $\mathrm{PD}$-induced changes in delta power. On the other hand, a significant elevation in theta, alpha and beta band power was observed in saline-treated group in comparison with vehicle group $(p<0.005, p<0.0005$ and $p<0.05$, respectively). Similarly, OT treatment significantly reversed all PD-induced alterations in EEG (Fig. 7).

We also evaluated the alterations in low beta $(12-20 \mathrm{~Hz})$ and high beta $(20-30 \mathrm{~Hz})$ bands following rotenone treatment. There was no statistically significant difference in low beta and high beta bands between vehicle-treated and saline-treated groups. Interestingly, OT administration significantly enhanced low beta power compare to saline treatment $(79.6 \%$ vs. $73.4, p<0.05)$ whereas no significant change was found in high beta power (Fig. 8). 

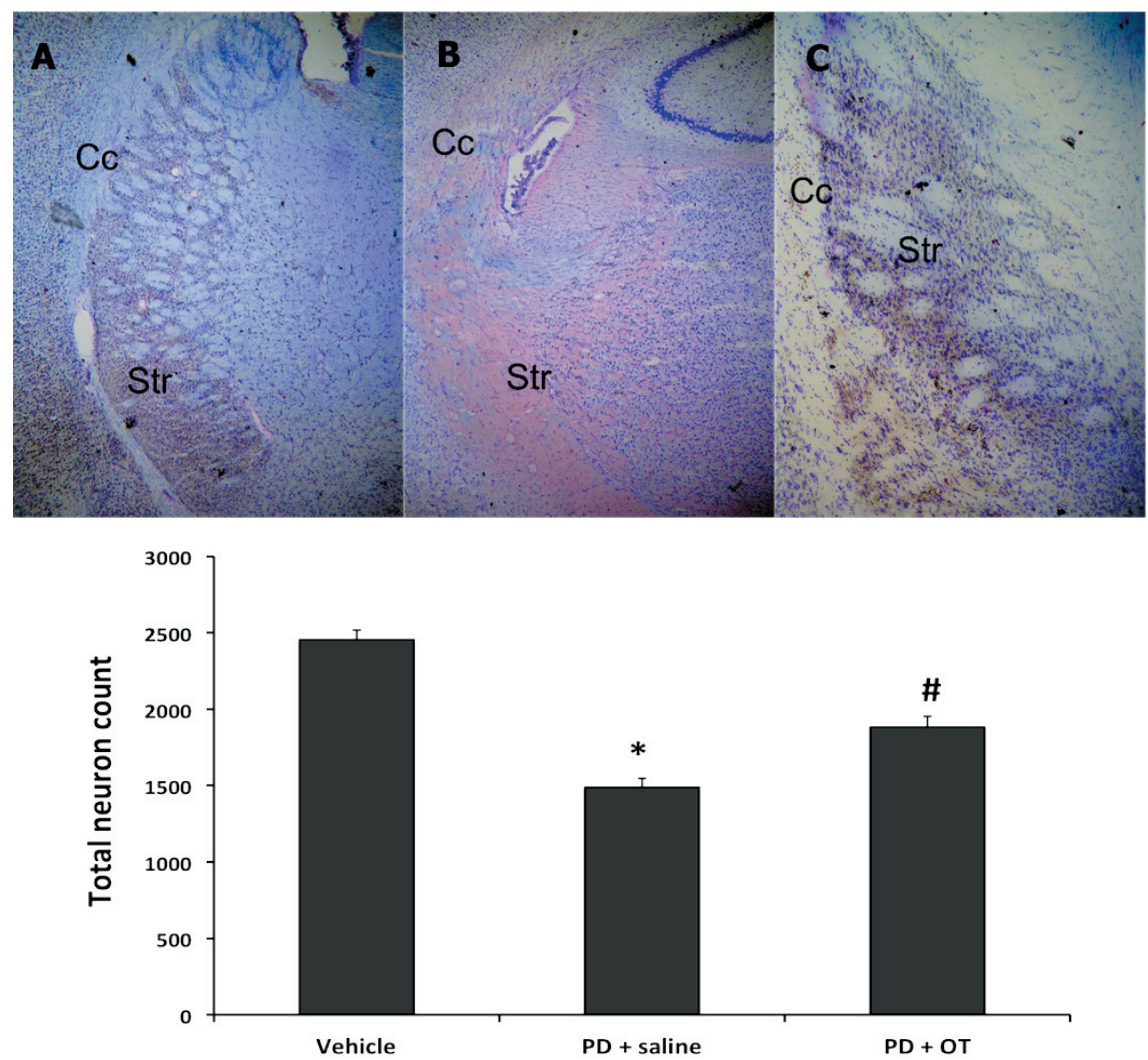

Figure 4. Evaluation of cell loss in the striatum. A. Vehicle (DMSO group). B. Saline-treated PD group. C. OT-treated PD group. Total neuron counts were performed in six sections per studied group by an image analysis system. ${ }^{*} p<0.0005 v s$. vehicle and $\# p<0.005$ $v$ s.saline-treated group. Bars represent means \pm S.E.M. Scale bars represent $125 \mu \mathrm{m}$. Cc, Corpus callosum; OT, oxytocin; PD, Parkinson's disease; Str, striatum.

\section{Discussion}

The primary findings of the present study were that unilateral lesion of the dopaminergic neurons significantly caused an increase in the striatal LFPs and systemic injection of OT could successfully suppress the exaggerated oscillations in rotenone-lesioned rats. These results were accompanied by the improvement of behavioral and histological changes.

Rotenone, as an environmental toxin, specifically affects electron transport chain in mitochondria and causes reactive oxygen species (ROS) overproduction within the cells (Greenamyre et al. 2003; Cannon and Greenamyre 2011). As confirmed by previous studies, dopaminergic neurons are more vulnerable to the prolonged exposure of rotenone than the other neurons including GABAergic, cholinergic or serotonergic (Heikkila et al. 1985; MareySemper et al. 1995; Sherer et al. 2003; Saravanan et al. 2005). Intracerebral administration of rotenone can lead progressive neuropathological changes in the nigrostriatal pathway mimicking idiopathic PD (Saravanan et al. 2005). Systemic administrations of rotenone also cause severe depletion of striatal dopamine levels in rats, however, these models have some limitations due to its peripheral toxicity and high mortality in animals. In the present study, rotenone-treated animals developed motor and postural deficits characteristic of PD, such as hypokinesia, freezing and flexed posture, at the end of the first week following stereotaxic surgery. Furthermore, both Nissl staining and TH immunohistochemistry confirmed a marked decrease of nigrostriatal dopaminergic neurons in rotenone-treated rats. Despite the fact that the current study suggests a highly reproducible procedure in terms of the behavioral and pathological features of $\mathrm{PD}$, the variability observed in toxin-induced PD models range from none to nearly complete dopaminergic lesions is interesting (Ferrante et al. 1997; Betarbet et al. 2000; Sherer et al. 2003b; Zhu et al. 2004). This variability is most likely due to differences in the injection site (injection of toxin into the SNc vs. medial forebrain bundle), dosage of toxin (single $v s$. repeated) or species examined (rat $v s$. mouse).

Previous studies have revealed that some of the striatal $\mathrm{TH}+$ neurons also express the enzyme glutamate decarboxylase (GAD) and therefore, these neurons appear to represent a particular subtype of GABA-ergic striatal interneurons capable of producing both GABA and dopamine (DA). Furthermore, the quantity of these neurons was reported to increase significantly in parkinsonian rodents and monkeys compared with controls (Tashiro et al. 1989; Betarbet et al. 1997; Tandé et al. 2006). Tandé et al. have indicated that 

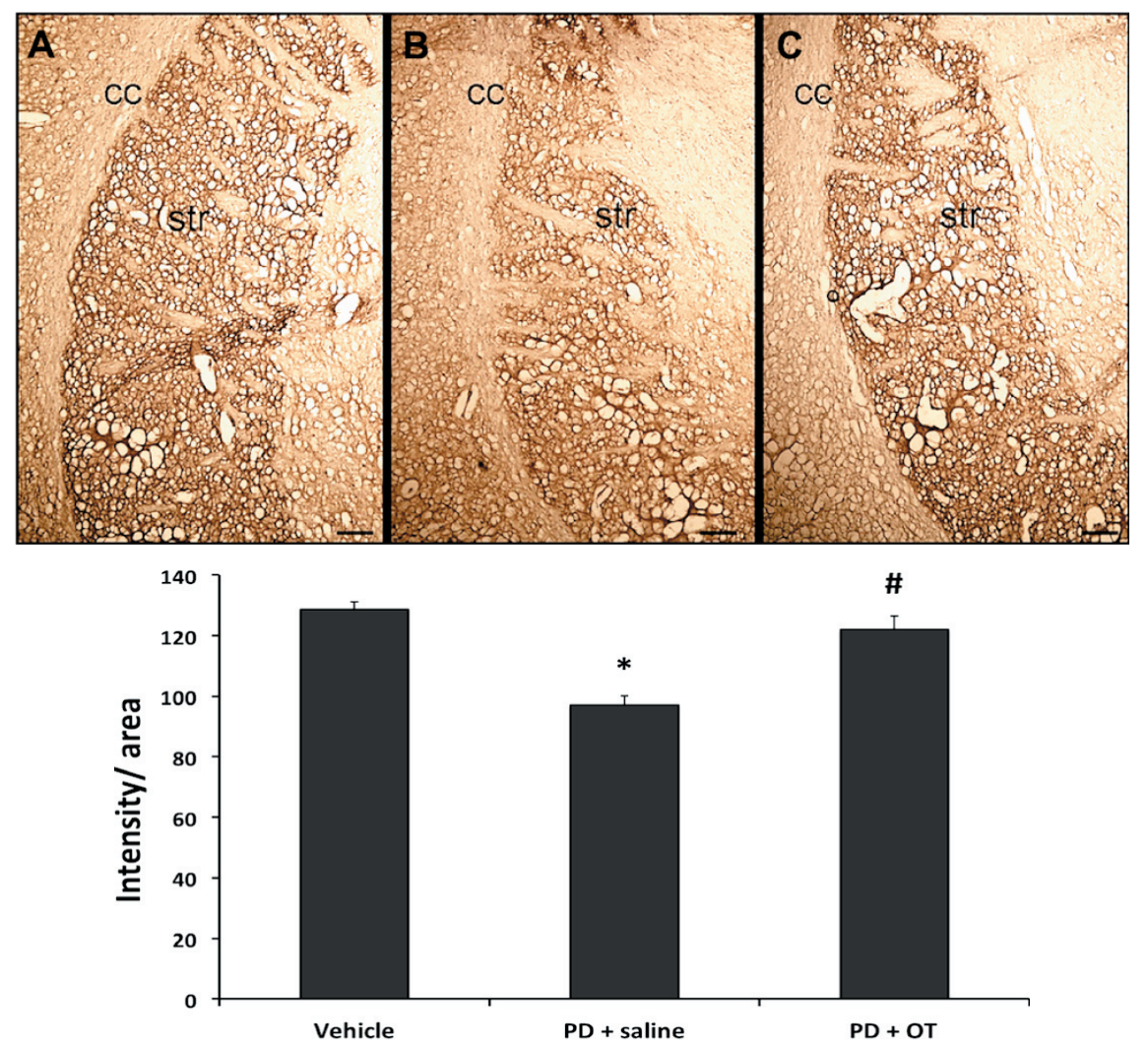

Figure 5. Tyrosine hydroxylase immunohistochemistry. A. Vehicle (DMSO group). B. Saline-treated PD group. C. OT-treated PD group. Quantification of the optical density of tyrosine hydroxylase immunostaining in the striatum revealed significant difference between the groups. ${ }^{\star} p<0.0005$ $v s$. vehicle and $\# p<0.005$ vs.salinetreated group. Bars represent means \pm S.E.M. Scale bars represent $125 \mu \mathrm{m}$. For abbreviations, see Fig. 4.

$\mathrm{TH}+$ neurons that appear after dopamine depletion in the striatum of aged macaques do not result from neurogenesis but rather from a phenotypic shift of pre-existing neurons (Tandé et al. 2006). On the other hand, in a recent study, it has been demonstrated that these neurons appear in the striatum as early as 3 days after a 6-OHDA lesion but by 1 week after the lesion, the number of $\mathrm{TH}+$ neurones starts to decline and this decline lasts significantly over time (Darmopil et al. 2008).

In recent years, oscillatory activity in the basal ganglia has attracted a great deal of interest because it is thought to be essential for both normal physiological processing of voluntary movement and pathophysiology of PD. Two distinct methods, measuring of single-/multiunit activity and LFPs, are often used to evaluate the frequency of synchronized and/or oscillatory activity in networks of neurons. Single-/ multiunit activity represents the action potential discharges of one cell or a small group of neurons, whereas LFPs are dominated by synchronized, subthreshold and, to a smaller degree, suprathreshold events in much larger populations of neurons (Berke et al. 2004). Electrophysiological studies have shown that dopamine depletion has significant effects on synchronization and oscillatory activity in the nigrastriatal pathway (Brown 2003, 2006; Hammond et al. 2007; Moran et al. 2010). LFPs recorded from the subthalamic nucleus (STN) in human with PD have revealed increased power in the beta oscillations supporting an abnormal synchrony among basal ganglia and cortical circuits (Brown 2003; Kühn et al. 2004, 2006). Similar to the human studies, experimental animal models of PD have demonstrated that loss of dopamine neurons significantly increased beta frequency band recorded from the STN and cortex (Sharott et al. 2005). Furthermore, it has been reported that high beta LFPs $(25-40 \mathrm{~Hz})$ recorded from substantia nigra was selectively increased in the dopamine-depleted hemisphere than in non- lesioned and control hemisphere during motor activity (Avila et al. 2010).

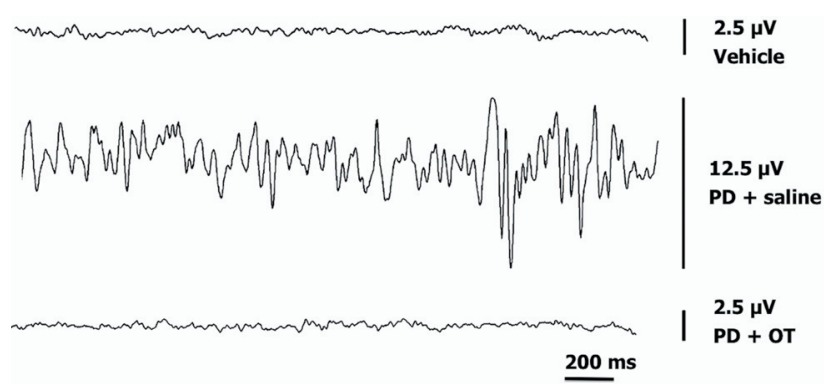

Figure 6. Examples of EEG recordings from the striatum of vehicle, saline-treated and OT-treated PD rats. For abbreviations, see Fig. 4. 


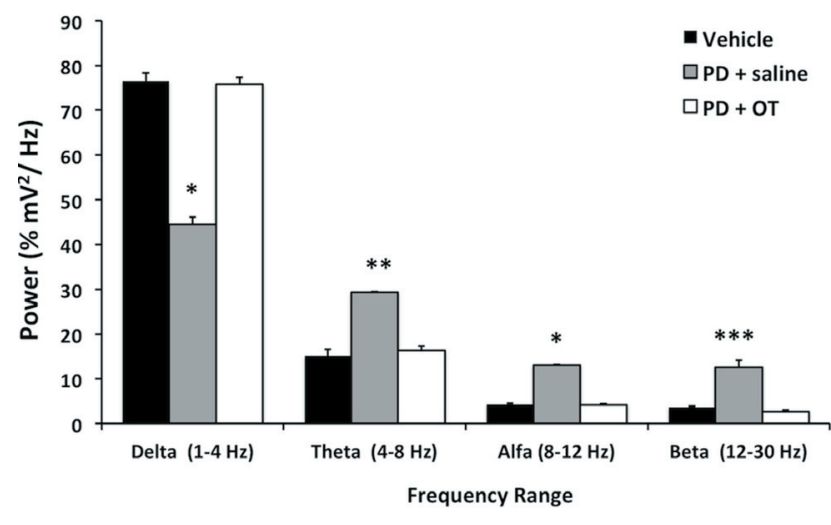

Figure 7. Striatal EEG and its frequency bands (percent of total power). Data are shown as mean \pm S.E.M. Statistical evaluation was performed by one-way ANOVA followed by Tukey's HSD post-hoc test $(n=6-7) ;{ }^{\star} p<0.0005,{ }^{* *} p<0.005$ and ${ }^{* * *} p<0.05 v s$. vehicle and OT-treated group. For abbreviations, see Fig. 4.

Electrical activity of striatal neurons is modulated by dopamine and degeneration of nigrostriatal pathway causes long-lasting changes on spontaneous activity of striatal neurons. Dopamine tonically prevents striatal acetylcholine release under physiological conditions by stimulating $\mathrm{D} 2$ receptors, and inhibition of $\mathrm{D} 2$ receptors or depletion of striatal dopamine can cause increased levels of acetylcholine in the striatum (DeBoer et al. 1996; Ikarashi et al. 1997). In addition, corticostriatal glutamatergic pathways can enhance their activities following nigrostriatal lesion (Meshul et al. 1999). Although there are controversial results regarding the striatal activity in $\mathrm{PD}$, our findings confirmed the association between dopamine depletion and increased oscillatory activity in the striatum. In addition, we observed a non-significant decrease in low beta and elevation in high beta band power in rotenone-lesioned rats. These results are in agreement with previous observations. Vorobyov et al. (2003) have reported a decrease in low beta $(12.6-17.5 \mathrm{~Hz})$ and an increase in high beta band $(17.6-27.5 \mathrm{~Hz})$ power in the striatum of 6-OHDA lesioned rats, which are modified by apomorphine and MK-801, a NMDA receptor blocker. More recently, based on experimental and computational models, it has been suggested that dopamine depletion and increased striatal cholinergic activity can lead to enhanced beta frequency oscillations in the striatum (McCarthy et al. 2011).

Although the functional physiological importance of both normal and pathological beta rhythms remains to be clarified, recent observations have indicated a considerable correlation between the abnormal rhythms and movement impairments in PD patients. Moreover, many chemicals including anti-parkinsonian drugs and deep brain stimulation (DBS) can modify oscillatory activity in human and animals (Wichmann et al. 1994; Brown 2003; Lehmkuhle et al. 2009). Therefore, any therapy, which can lessen the exaggerated neuronal activity, would attenuate clinical symptoms in $\mathrm{PD}$ patients.

In the current study, treatment of rats with $160 \mu \mathrm{g} / \mathrm{kg} / \mathrm{day}$ OT for 3 weeks successfully reduced the rotenone-induced neurotoxicity and suppressed the increased activity in EEG. To our knowledge, there is no use of oxytocin in a similar protocol and therefore we cannot compare the dosage regime used in the present study with others. However, previous experimental studies have recommended that pharmacological doses of OT between 100-1000 $\mu \mathrm{g} / \mathrm{kg}$ are more effective in preventing and/or lessening tissue damage (Petersson et al. 2001; Iseri et al. 2005; Leuner et al. 2012; Erbas et al. 2013). Moreover, in a recent study, we found that both $80 \mu \mathrm{g} / \mathrm{kg}$ OT and $160 \mu \mathrm{g} / \mathrm{kg}$ OT could inhibit pentylenetetrazol-induced seizures and significantly improve EEG abnormalities in rats (Erbas et al. 2012a).

According to results of our study, we propose that OT can act as a neuroprotective agent and reduce cell death in the injured striatum because of its anti-inflammatory, anti-apoptotic, anti-oxidant and trophic effects. Indeed, many studies, both in vitro and in vivo, have suggested the cytoprotective and trophic potential of oxytocin using various experimental models (Iseri et al. 2005; Ceanga et al. 2010; Alizadeh et al. 2012; Bakos et al. 2012; Erbas et al. 2012b; Leuner et al. 2012). For instance, preincubation of cells with OT reduces toxicity and induce cell viability in neuronal cell cultures exposed to 6-OHDA (Bakos et al. 2012). Recently, we have demonstrated the beneficial effect of OT against sepsis-induced polyneuropathy by evaluating electromyography (EMG) changes and biochemical parameters including plasma TNF- $\alpha$, malondialdehyde and total anti-oxidant capacity in critical illness (Erbas et al. 2013).

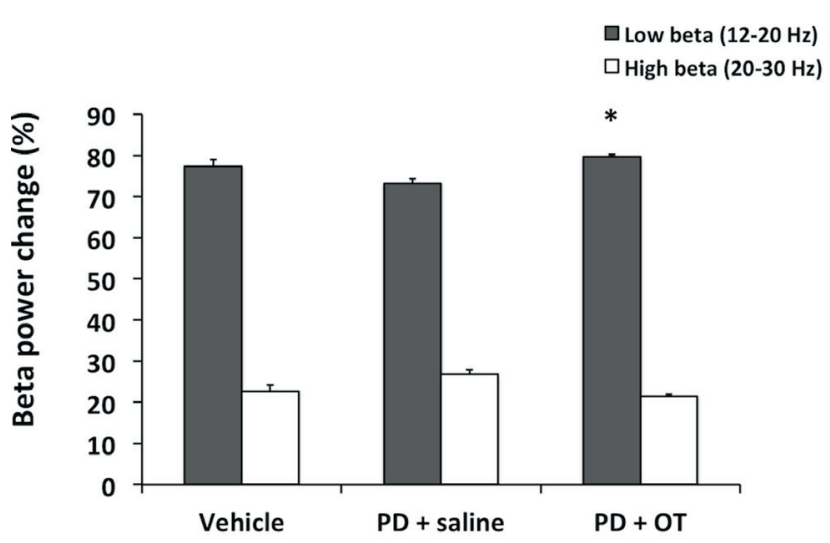

Figure 8. The effects of oxytocin on the striatal beta oscillations in experimentally induced- PD rats. Data are expressed as mean values \pm S.E.M. Statistical evaluation was performed by one-way ANOVA followed by Tukey's HSD post-hoc test $(n=6-7) ;{ }^{*} p<0.005$ vs. saline-treated group. For abbreviations, see Fig. 4. 
Taken together, our findings support that injury of dopaminergic neurons generate exaggerated neuronal oscillations in the striatum and oxytocin may have some inhibitory effects on neuronal activity in PD. Investigating how striatal activity is altered by oxytocin may disclose new alternative therapeutic approaches for Parkinson's disease.

Conflict of interest: The authors report no declarations of interest.

\section{References}

Alam M., Schmidt W. J. (2002): Rotenone destroys dopaminergic neurons and induces parkinsonian symptoms in rats. Behav. Brain. Res. 136, 317-324 http://dx.doi.org/10.1016/S0166-4328(02)00180-8

Alizadeh A. M., Faghihi M., Khori V., Sohanaki H., Pourkhalili K., Mohammadghasemi F., Mohsenikia M. (2012): Oxytocin protects cardiomyocytes from apoptosis induced by ischemia-reperfusion in rat heart: role of mitochondrial ATP-dependent potassium channel and permeability transition pore. Peptides 36, 71-77 http://dx.doi.org/10.1016/j.peptides.2012.03.023

Avila I., Parr-Brownlie L. C., Brazhnik E., Casta-eda E., Bergstrom D. A., Walters J. R. (2010): Beta frequency synchronization in basal ganglia output during rest and walk in a hemiparkinsonian rat. Exp. Neurol. 221, 307-319 http://dx.doi.org/10.1016/j.expneurol.2009.11.016

Bakos J., Strbak V., Ratulovska N., Bacova Z. (2012): Effect of oxytocin on neuroblastoma cell viability and growth. Cell. Mol. Neurobiol. 32, 891-896 http://dx.doi.org/10.1007/s10571-012-9799-1

Berke J. D., Okatan M., Skurski J., Eichenbaum H. B. (2004): Oscillatory entrainment of striatal neurons in freely moving rats. Neuron 43, 883-896 http://dx.doi.org/10.1016/j.neuron.2004.08.035

Betarbet R., Turner R., Chockkan V., DeLong M. R., Allers K. A., Walters J., Levey A. I., Greenamyre J. (1997): Dopaminergic neurons intrinsic to the primate striatum. J. Neurosci. 17, 6761-6768

Betarbet R., Sherer T. B., MacKenzie G., Garcia-Osuna M., Panov A. V., Greenamyre J. T. (2000): Chronic systemic pesticide exposure reproduces features of Parkinson's disease. Nat. Neurosci. 12, 1301-1306

Brown P. (2003): Oscillatory nature of human basal ganglia activity: relationship to the pathophysiology of Parkinson's disease. Mov. Disord. 18, 357-363 http://dx.doi.org/10.1002/mds.10358

Brown P. (2006): Bad oscillations in Parkinson's disease. J. Neural. Transm. 70, 27-30 http://dx.doi.org/10.1007/978-3-211-45295-0_6

Buzsáki G. (2002): Theta oscillations in the hippocampus. Neuron 33, 325-340 http://dx.doi.org/10.1016/S0896-6273(02)00586-X

Cannon J. R., Greenamyre J. T. (2011): The role of environmental exposures in neurodegeneration and neurodegenerative diseases. Toxicol. Sci. 124, 225-250 http://dx.doi.org/10.1093/toxsci/kfr239
Cannon J. R., Tapias V., Na H. M., Honick A. S., Drolet R. E., Greenamyre J.T. (2009): A highly reproducible rotenone model of Parkinson's disease. Neurobiol. Dis. 34, 279-290 http://dx.doi.org/10.1016/j.nbd.2009.01.016

Ceanga M., Spataru A., Zagrean A. (2010): Oxytocin is neuroprotective against oxygen-glucose deprivation and reoxygenation in immature hippocampal cultures. Neurosci. Lett. 477, 15-18 http://dx.doi.org/10.1016/j.neulet.2010.04.024

Darmopil S., Mu-etón-Gómez V. C., de Ceballos M. L., Bernson M., Moratalla R. (2008): Tyrosine hydroxylase cells appearing in the mouse striatum after dopamine denervation are likely to be projection neurones regulated by L-DOPA. Eur. J. Neurosci. 27, 580-592 http://dx.doi.org/10.1111/j.1460-9568.2008.06040.x

Dauer W., Przedborski S. (2003): Parkinson's disease: mechanisms and models. Neuron 39, 889-909 http://dx.doi.org/10.1016/S0896-6273(03)00568-3

DeBoer P., Heeringa M. J., Abercrombie E. D. (1996): Spontaneous release of acetylcholine in striatum is preferentially regulated by inhibitory dopamine D2 receptors. Eur. J. Pharmacol. 317, $257-262$ http://dx.doi.org/10.1016/S0014-2999(96)00761-3

Erbaş O., Yılmaz M., Korkmaz H. A., Bora S., Evren V., Peker G. (2012a): Oxytocin inhibits pentylentetrazol-induced seizures in the rat. Peptides 40, 141-144 http://dx.doi.org/10.1016/j.peptides.2012.12.003

Erbaş O., Oltulu F., Taskiran D. (2012b): Amelioration of rotenoneinduced dopaminergic cell death in the striatum by oxytocin treatment. Peptides 38, 312-317 http://dx.doi.org/10.1016/j.peptides.2012.05.026

Erbaş O., Ergenoglu A. M., Akdemir A., Yeniel A. O., Taskiran D. (2013): Comparison of melatonin and oxytocin in the prevention of critical illness polyneuropathy in rats with experimentally induced sepsis. J. Surg. Res. 183, 313-320

http://dx.doi.org/10.1016/j.jss.2012.11.043

Ferrante R. J., Schulz J. B., Kowall N. W., Beal M. F. (1997): Systemic administration of rotenone produces selective damage in the striatum and globus pallidus, but not in the substantia nigra. Brain Res. 753, 157-162 http://dx.doi.org/10.1016/S0006-8993(97)00008-5

Gimpl G., Fahrenholz F. (2011): The oxytocin receptor system: structure, function, and regulation. Physio. Rev. 81, 630-668

Greenamyre J. T., Betarbet R., Sherer T. B. (2003): The rotenone model of Parkinson's disease: genes, environment and mitochondria. Parkinsonism Relat. Disord. 9, 59-64 http://dx.doi.org/10.1016/S1353-8020(03)00023-3

Gutkowska J., Jankowski M. (2009): Oxytocin: old hormone, new drug. Pharmaceuticals 2, 168-183 http://dx.doi.org/10.3390/ph203168

Hammond C., Bergman H., Brown P. (2007): Pathological synchronization in Parkinson's disease: networks, models and treatments. Trends. Neurosci. 30, 357-364 http://dx.doi.org/10.1016/j.tins.2007.05.004

Heikkila R. E., Nicklas W. J., Vyas I., Duvoisin R. C. (1985): Dopaminergic toxicity of rotenone and the 1-methyl-4-phenylpyridinium ion after their stereotaxic administration to rats: implication for the mechanism of 1-methyl-4-phenyl-1,2,3,6tetrahydropyridine toxicity. Neurosci. Lett. 62, 389-394 
http://dx.doi.org/10.1016/0304-3940(85)90580-4

Ikarashi Y., Takahashi A., Ishimaru H., Arai T., Maruyama Y. (1997): Regulation of dopamine D1 and D2 receptors on striatal acetylcholine release in rats. Brain Res. Bull. 43, 107-115 http://dx.doi.org/10.1016/S0361-9230(96)00351-6

Iseri S. O., Sener G., Saglam B., Gedik N., Ercan F., Yegen B. C. (2005): Oxytocin protects against sepsis-induced multiple organ damage: Role of neutrophils. J. Surg. Res. 126, 73-81 http://dx.doi.org/10.1016/j.jss.2005.01.021

Jin F., Wu Q., Lu Y. F., Gong Q. H., Shi J. S. (2008): Neuroprotective effect of resveratrol on 6-OHDA-induced Parkinson's disease in rats. Eur. J. Pharmacol. 600, 78-82 http://dx.doi.org/10.1016/j.ejphar.2008.10.005

Kühn A. A., Williams D., Kupsch A., Limousin P., Hariz M., Schneider G. H., Yarrow K., Brown P. (2004): Event-related beta desynchronization in human subthalamic nucleus correlates with motor performance. Brain 127, 735-746 http://dx.doi.org/10.1093/brain/awh106

Kühn A. A., Kupsch A., Schneider G. H., Brown P. (2006): Reduction in subthalamic $8-35 \mathrm{~Hz}$ oscillatory activity correlates with clinical improvement in Parkinson's disease. Eur. J. Neurosci. 23, 1956-1960 http://dx.doi.org/10.1111/j.1460-9568.2006.04717.x

Lehmkuhle M. J., Bhangoo S. S., Kipke D. R. (2009): The electrocorticogram signal can be modulated with deep brain stimulation of the subthalamic nucleus in the hemiparkinsonian rat. J. Neurophysiol. 102, 1811-1820 http://dx.doi.org/10.1152/jn.90844.2008

Leuner B., Caponiti J. M., Gould E. (2012): Oxytocin stimulates adult neurogenesis even under conditions of stress and elevated glucocorticoids. Hippocampus 22, 861-868 http://dx.doi.org/10.1002/hipo.20947

Marcotte E. R., Chugh A., Mishra R. K., Johnson R. L. (1998): Protection against MPTP treatment by an analog of Pro-LeuGly-NH2 (PLG, MIF-1). Peptides 19, 403-406 http://dx.doi.org/10.1016/S0196-9781(97)00321-5

Marey-Semper I., Gelman M., Lévi-Strauss M. (1995): A selective toxicity toward cultured mesencephalic dopaminergic neurons is induced by the synergistic effects of energetic metabolism impairment and NMDA receptor activation. J. Neurosci. 15, 5912-5918

McCarthy M. M., Moore-Kochlacs C., Gu X., Boyden E. S., Han X., Kopell N. (2011): Striatal origin of the pathologic beta oscillations in Parkinson's disease. Proc. Natl. Acad. Sci. U. S. A. 108, 11620-11625 http://dx.doi.org/10.1073/pnas.1107748108

Meshul C. K., Emre N., Nakamura C. M., Allen C., Donohue M. K., Buckman, J. F. (1999): Time-dependent changes in striatal glutamate synapses following a 6-hydroxydopamine lesion. Neuroscience 88, 1-16 http://dx.doi.org/10.1016/S0306-4522(98)00189-4

Moran R. J., Mallet N., Litvak V., Dolan R. J., Magill P. J., Friston K. J., Brown P. (2011): Alterations in brain connectivity underlying beta oscillations in Parkinsonism. PLoS. Comput. Biol. 8, e1002124 http://dx.doi.org/10.1371/journal.pcbi.1002124

Paxinos G., Watson C. (1998): The Rat Brain: In Stereotaxic Coordinates. 4th ed. San Diego, CA: Academic Press
Petersson M., Wiberg U., Lundeberg T., Uvnäs-Moberg K. (2001): Oxytocin decreases carrageenan induced inflammation in rats. Peptides 22, 1479-1484 http://dx.doi.org/10.1016/S0196-9781(01)00469-7

Rutishauser U., Ross I. B., Mamelak A. N., Schuman E. M. (2010): Human memory strength is predicted by theta-frequency phase-locking of single neurons. Nature 464, 903-907 http://dx.doi.org/10.1038/nature08860

Saravanan K. S., Sindhu K. M., Mohanakumar K. P. (2005): Acute intranigral infusion of rotenone in rats causes progressive biochemical lesions in the striatum similar to Parkinson's disease. Brain Res. 1049, 147-155 http://dx.doi.org/10.1016/j.brainres.2005.04.051

Sharott A., Magill P. J., Harnack D., Kupsch A., Meissner W., Brown P. (2005): Dopamine depletion increases the power and coherence of beta oscillations in the cerebral cortex and subthalamic nucleus of the awake rat. Eur. J. Neurosci. 5, 1413-1422 http://dx.doi.org/10.1111/j.1460-9568.2005.03973.x

Sherer T. B., Kim J. H., Betarbet R., Greenamyre J. T. (2003): Subcutaneous rotenone exposure causes highly selective dopaminergic degeneration and alpha-synuclein aggregation. Exp. Neurol. 179, 9-16 http://dx.doi.org/10.1006/exnr.2002.8072

Tandé D., Höglinger G., Debeir T., Freundlieb N., Hirsch E. C., François C. (2006): New striatal dopamine neurons in MPTPtreated macaques result from a phenotypic shift and not neurogenesis. Brain 129, 1194-2000 http://dx.doi.org/10.1093/brain/awl041

Tashiro Y., Sugimoto T., Hattori T., Uemura Y., Nagatsu I., Kikuchi H., Mizuno N. (1989): Tyrosine hydroxylase-like immunoreactive neurons in the striatum of the rat. Neurosci. Lett. 97, 6-10 http://dx.doi.org/10.1016/0304-3940(89)90130-4

Vandecasteele M., Deniau J. M., Glowinski J., Venance L. (2007): Electrical synapses in basal ganglia. Rev. Neurosci. 18, 15-35 http://dx.doi.org/10.1515/REVNEURO.2007.18.1.15

Vorobyov V. V., Schibaev N. V., Morelli M., Carta A. R. (2003): EEG modifications in the cortex and striatum after dopaminergic priming in the 6-hydroxydopamine rat model of Parkinsons disease. Brain. Res. 972, 177-185 http://dx.doi.org/10.1016/S0006-8993(03)02528-9

Wichmann T., Bergman H., DeLong M. R. (1994): The primate subthalamic nucleus. III. Changes in motor behavior and neuronal activity in the internal pallidum induced by subthalamic inactivation in the MPTP model of Parkinsonism. J. Neurophysiol. 72, 521-530

Xiong N., Huang J., Zhang Z., Zhang Z., Xiong J., Liu X., Jia M., Wang F., Chen C., Cao X., Liang Z., Sun S., Lin Z., Wang T. (2009): Stereotaxical infusion of rotenone: a reliable rodent model for Parkinson's disease. Plos One 4, e7878 http://dx.doi.org/10.1371/journal.pone.0007878

Zhu C., Vourc'h P., Fernagut P. O., Fleming S. M., Lacan S., Dicarlo C. D., Seaman R. L., Chesselet M. F. (2004): Variable effects of chronic subcutaneous administration of rotenone on striatal histology. J. Comp. Neurol. 478, 418-426 http://dx.doi.org/10.1002/cne.20305

Received: December 11, 2012

Final version accepted: April 19, 2013 